\title{
Modelo Integrado de Mapas de Escoamento, Queda de Pressão e Transmissão de Calor na Produção de Petróleo
}

\section{Integrated Model of Flow Maps, Pressure Drop and Heat Transfer in oil production}

1 Ernani Valente de Mesquita Júnior ernanivm@gmail.com

2 Alexandre José da Silva

1 Mestrando, Universidade Federal Fluminense.
2 Prof. Dr., Universidade Federal Fluminense.

\section{Resumo}

A proposta deste artigo consiste no desenvolvimento de um modelo de previsão do escoamento bifásico e transmissão de calor em unidades offshore. Esse modelo de previsão considera sete padrões de escoamento: estratificado suave, estratificado ondulado, estratificado ondulado com arraste de líquido, anular, anular com arraste de líquido, intermitente e bolhas dispersas. 0 modelo é dado a partir das vazões mássicas da fase líquida e gasosa, como também das propriedades físicas de ambas as fases expressas pelo número de Froude, da inclinação da tubulação com a direção horizontal e de seu diâmetro interno. Fornece também uma estimativa para o gradiente de pressão e queda da temperatura ao longo da tubulação.

\section{Palavras-chave}

Modelo integrado; escoamento bifásico; padrões de escoamento; transmissão de calor; petróleo.

\begin{abstract}
The purpose of this article is to develop a predictive model of two-phase flow and heat transfer in offshore units. This model provides seven patterns of flow: stratified smooth, stratified wavy, stratified wavy entrained, annular, annular entrained, slug and dispersed bubbles. The model starts with the mass flow rates of gaseous and liquid phase, as well as the physical properties of both phases expressed by the Froude number, pipe inclination to the horizontal direction and its inner diameter. This model provides an estimation for the pressure gradient and temperature drop along the pipe.
\end{abstract}

\section{Keywords}

Integrated model, two-phase, flow pattern, heat transfer, oil.

\section{Como você deve citar?}

MESQUITA JÚNIOR, Ernani Valente de; SILVA, Alexandre José da. Modelo Integrado de Mapas de Escoamento, Queda de Pressão e Transmissão de Calor na Produção de Petróleo. Cadernos UniFOA, Volta Redonda, n. 31, p. 23-45, ago. 2016. 


\section{INTRODUÇÃO}

O Petróleo, na natureza, pode ser encontrado principalmente em espaços porosos em rochas, denominados reservatórios. Esses, geralmente, podem ser encontrados a muitos metros abaixo do nível do mar, coluna d'agua com mais de $2000 \mathrm{~m}$ de profundidade.

Para encontrar reservatórios em regiões profundas foram necessários investimentos em tecnologias que viabilizassem o custo de produção, tendo em vista que esse processo envolve três fases consecutivas para verificar essa viabilidade: a primeira consiste na viabilidade da prospecção, por meio de uso de métodos geológicos, geofísicos e sísmicos para o estudo das estruturas do subsolo favorável à existência de petróleo; a segunda, na perfuração, onde será verificada a existência de acumulações de hidrocarbonetos em um determinado local; e, por último, a avaliação de formações, para verificar o potencial de produção de uma acumulação de petróleo descoberta, (THOMAS, 2001).

As condições de temperatura e pressão nesses reservatórios são muito maiores que os estabelecidos em condições básicas e, mesmo em condições ideais de escoamento monofásico, sofrem variações nas condições termodinâmicas, fazendo com que o hidrocarboneto sofra mudança em seu estado inicial, tornando-o multifásico.

A produtividade de poços de petróleo está ligada às condições de pressão no reservatório, profundidade, comprimento e das perdas de pressão nas tubulações de produção que ligam o reservatório às unidades na superfície. Para o projeto e eficiente operação do sistema de produção é necessário o conhecimento preciso das condições do escoamento que envolve diferentes fases como gás, óleo e, até mesmo, água. (LYONS et. al., 2016). A previsão de mapas de escoamento e cálculo das perdas de pressão em escoamentos bifásicos têm sido objeto de estudo de vários autores. Uma revisão da literatura nesse aspecto pode ser encontrada em Jerez-Carrizales et. al. (2015).

Os modelos para determinação do regime de escoamento têm sido estabelecidos ao longo de várias décadas na literatura, principalmente a partir das décadas de 60 e 70 do século $X X$, através de renomados autores, como Zuber e Findlay (1965), Taitel e Dukler (1976), Oliemans e Pots (1986).

A maioria dos autores identifica pelo menos quatro regimes de escoamento como principais regimes que ocorrem no escoamento simultâneo de um gás e um líquido em uma tubulação, conforme apresentado abaixo na figura 1: 
Figura 1 - Regimes de escoamento

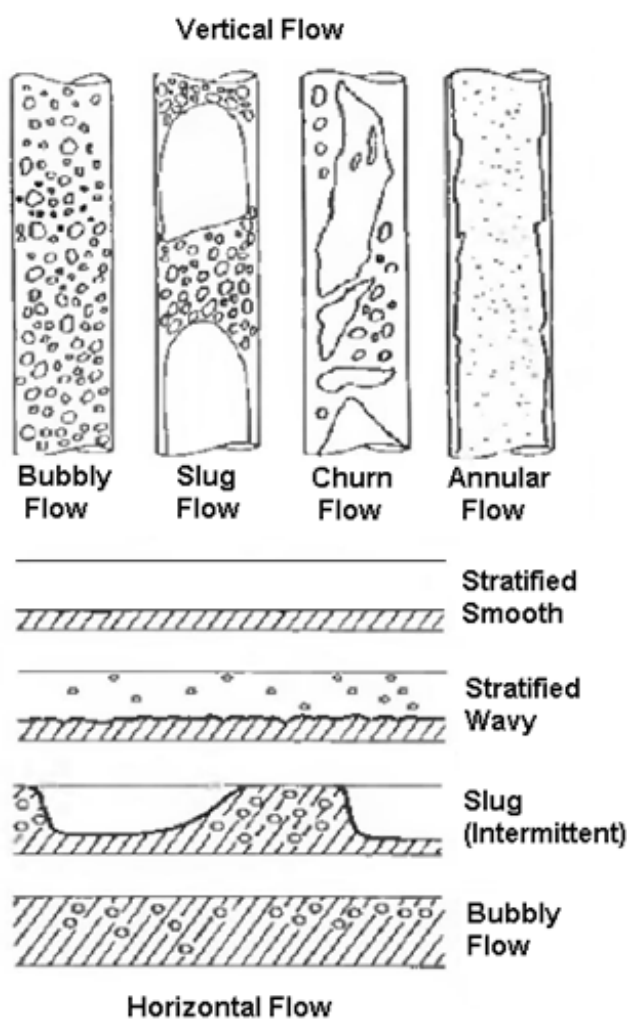

Fonte: dos autores.

O regime estratificado pode ser suave, stratified smooth, ondulado e ondulado com arraste de líquido, stratified wave e stratified wave entrained. Ocorrendo frequentemente em tubulações horizontais ou pequenas inclinações, o regime estratificado é caracterizado por apresentar uma camada de líquido na parte inferior da tubulação. A alta velocidade da fase gasosa em relação à velocidade da fase líquida pode causar fortes ondulações na interface gás-líquido, caracterizando o regime estratificado ondulado.

O regime anular e anular com arraste de líquido, annular e anullar entrained, é caracterizado pela continuidade e concentração da fase gasosa na região central da tubulação, onde a mesma se desloca em velocidade mais alta que a fase líquida, que preenche todo o perímetro de contato com a parede da tubulação, na forma de um filme de líquido e, eventualmente, também na forma de gotículas distribuídas na fase gasosa, caracterizando o regime anular com arraste de líquido. Ocorrendo uma redução na velocidade da fase gasosa abaixo de certo valor crítico, o filme de líquido desaba e o escoamento recai no regime intermitente ou slug flow. Esse regime ocorre predominantemente com a tubulação na direção vertical, mas pode também estar presente em tubulações horizontais ou pouco inclinadas.

A maior parte do gás concentra-se em largas bolhas com diâmetros próximos ao diâmetro da tubulação. Essas bolhas são separadas por golfadas de líquido contínuo que atravessam a tubulação. Essas golfadas podem conter pequenas bolhas de gás. No regime slug flow, a fase gasosa e líquida têm ambas significantes efeitos no gradiente de pressão. Esse padrão é relativamente bem comportado e ordenado, na forma como se repetem alternadamente a fase líquida e gasosa. 
No regime de bolhas dispersas, dispersed bubble, a tubulação é preenchida com a fase gasosa de maneira distribuída na forma de bolhas discretas na fase líquida contínua, podendo ocorrer tanto no escoamento horizontal como no vertical. As bolhas têm efeito apenas indireto na queda de pressão, através da modificação dos fenômenos de transporte envolvidos e propriedades físicas, como a massa específica da mistura

Essas formas de escoamento são as mais básicas, podendo apresentar variações quanto à agitação ou ondas nas interfaces, além da dispersão de gotas de líquido na fase gasosa, chamada, então, de entrained fluid. Outra possibilidade acontece no caso de ambas as fases apresentarem descontinuidade nas interfaces e uma forte agitação. Essa forma é, às vezes, chamada de transição, churn flow ou, ainda froth flow, não sendo consideradas no presente trabalho.

Para determinação do regime de escoamento, será implementada uma metodologia em que o objetivo principal é obter a queda de pressão no qual o sistema é submetido. Uma das principais características em um escoamento bifásico é o cálculo da fração de líquido na seção da tubulação para diferentes volumes, devido ao evento de atrito existente entre as fases, conhecido como holdup. Esse evento é diferente para cada tipo de regime de escoamento.

O algoritmo para a previsão dos padrões de escoamento utilizado baseia-se no modelo descrito por Oliemans e Pots em Crowe (2006), a partir das vazões mássicas de duas fases, líquida e gasosa, das propriedades físicas e geometria da tubulação, desde o poço até a unidade de exploração.

Após a implementação do código de determinação dos regimes, será acoplado ao sistema a transferência de calor por convecção natural e, dessa forma, analisar como os regimes comportam-se com a variação da inclinação da tubulação. (KIM; GHAJAR, 2006).

O coeficiente de transferência de calor bifásico está relacionado ao regime naquele determinado segmento da tubulação. A inclinação da tubulação tem influência significativa no regime de escoamento, logo influencia diretamente nas correlações desenvolvidas por Ghajar (2005) e Kim et. al. (2006).

O desenvolvimento dessa ferramenta de cálculo auxiliará na análise e produção de petróleo, tendo como premissa o escoamento desde o poço até a unidade de exploração.

\section{METODOLOGIA}

Por se tratar de um amplo conteúdo abordado, o presente trabalho não contempla o desenvolvimento de algumas variáveis apresentadas de forma objetiva. Contudo os desenvolvimentos dessas variáveis estão disponíveis em Crowe (2006).

O objetivo principal é obter a queda de pressão através da tubulação. Os modelos consideram o deslizamento entre as fases em cada regime de escoamento, o que leva à necessidade da determinação do holdup em cada um dos regimes.

O ponto de partida será obter o diâmetro interno da tubulação, $D$; rugosidade da parede interna da tubulação, $\varepsilon$; inclinação da tubulação com a horizontal, $\theta$; massa específica da fase líquida, $\rho_{L}$; massa específica da fase gasosa, $\rho_{G}$; viscosidade da fase líquida, $\mu_{L}$; viscosidade da fase gasosa, $\mu_{G}$; tensão superficial, $\sigma$; e os parâmetros do escoamento bifásico, velocidade superficial da fase líquida, $v_{S L}$; velocidade superficial da fase gasosa, $v_{S G}$; fração do volume de líquido, $\lambda_{L}$. Definidos por: 


$$
\begin{gathered}
A_{t}=\left(\pi D^{2}\right) / 4 \\
\mathrm{v}_{S L}=\dot{q}_{L} /\left(A_{t} \rho_{L}\right) \\
\mathrm{v}_{S G}=\dot{q}_{G} /\left(A_{t} \rho_{G}\right) \\
\mathrm{v}_{M}=\mathrm{v}_{S L}+\mathrm{v}_{S G} \\
\lambda_{L}=\mathrm{v}_{S L} / \mathrm{v}_{M}
\end{gathered}
$$

Seguem os modelos específicos para cada regime de escoamento.

\subsection{Regime de bolhas dispersas}

Assume-se que não existe variação radial da velocidade das bolhas, dada por:

$$
U_{b}=1,53\left[\frac{\sigma g \Delta \rho}{\rho_{L}^{2}}\right]^{1 / 4} \operatorname{sen} \theta
$$

Para um fluxo vertical, assume-se a velocidade do gás como sendo:

$$
\mathrm{v}_{G}=C_{o} \mathrm{v}_{M}+U_{b}
$$

Onde o parâmetro $C_{o^{\prime}}$, conhecido como parâmetro de distribuição reflete os efeitos da velocidade no centro da tubulação, com valor de 1,25. O holdup da fase gasosa e velocidade superficial da fase gasosa.

$$
\alpha_{G}=\frac{\mathrm{v}_{S G}}{\mathrm{v}_{G}}
$$

O gradiente de pressão, devido ao fator de atrito para esse tipo de mistura:

$\frac{d P}{d x}=-2 \frac{f_{m} \rho_{m} \mathrm{v}_{M}^{2}}{D}$

A massa específica dessa mistura é dada por:

$$
\rho_{m}=\alpha_{L} \rho_{L}+\alpha_{G} \rho_{G}
$$

O fator de atrito, $f_{m^{\prime}}$ é calculado a partir do número adimensional de Reynolds em função da velocidade da mistura das fases.

$$
R e_{m}=\frac{D \rho_{m} \mathrm{v}_{M}}{\mu_{L}}
$$

Substituindo as variáveis obtidas anteriormente na equação abaixo, é possível calcular o gradiente de pressão total, equação (12).

$$
-\frac{d p}{d x}=\tau_{W G} \frac{k_{G}}{A_{t}}+\tau_{W L} \frac{k_{L}}{A_{t}}+\left(\alpha_{G} \rho_{G}+\alpha_{L} \rho_{L}\right) g \operatorname{sen} \theta+\frac{d}{d x}\left(\frac{\rho_{G} \mathrm{v}_{S G}^{2}}{\alpha_{G}}+\frac{\rho_{L} \mathrm{v}_{S L}^{2}}{\alpha_{L}}\right)
$$




\subsection{Regime estratificado e anular}

Para o cálculo do gradiente de pressão total, é necessário, primeiramente, calcular o parâmetro de Lockhart-Martinelli, $X$ e de inclinação, $Y$, conforme equações abaixo.

$$
\begin{aligned}
& X=\left(\frac{f_{S L} \rho_{L} \mathrm{v}_{S L}^{2}}{f_{S G} \rho_{G} \mathrm{v}_{S G}^{2}}\right)^{1 / 2} \\
& Y=\frac{\sin \theta}{2 f_{S G} F r_{G}^{2}}
\end{aligned}
$$

As áreas das fases gasosa e líquida em uma seção da tubulação também estão em função da altura da camada de líquido, conforme as próximas equações.

$$
\begin{aligned}
& A_{L}=\frac{D^{2}}{4}\left(\cos ^{-1}\left(1-2 \frac{h_{L}}{D}\right)-2\left(1-2 \frac{h_{L}}{D}\right) \sqrt{\frac{h_{L}}{D}\left(1-\frac{h_{L}}{D}\right)}\right) \\
& A_{G}=\frac{D^{2}}{4}\left(\pi-\cos ^{-1}\left(1-2 \frac{h_{L}}{D}\right)+2\left(1-2 \frac{h_{L}}{D}\right) \sqrt{\frac{h_{L}}{D}\left(1-\frac{h_{L}}{D}\right)}\right)
\end{aligned}
$$

O holdup de líquido, $\alpha_{L^{\prime}}$ é obtido como raiz da expressão, proveniente da combinação dos balanços de quantidade de movimento das duas fases, formulado, originalmente, por Taitel e Dukler (1976):

$$
F=\tau_{w G} \frac{K_{G}}{A_{G}}-\tau_{w L} \frac{K_{L}}{A_{L}}+\tau_{i} K_{i}\left(\frac{1}{A_{L}}+\frac{1}{A_{G}}\right)-\left(\rho_{L}-\rho_{G}\right) g \operatorname{sen} \theta-\Delta \rho g D \cos \theta \frac{\partial h_{L} / D}{\partial \alpha_{L}} \frac{\partial \alpha_{L}}{\partial x}
$$

Os perímetros de contato da fase líquida, gasosa, interface, são definidos em função do ângulo de molhamento, , conforme equações (18) à (20).

$$
\begin{aligned}
& k_{L}=\frac{D \beta}{2}=\frac{D}{2} \cos ^{-1}\left(1-2 \frac{h_{L}}{D}\right) \\
& k_{G}=\frac{D}{2}(\pi-\beta)=\frac{D}{2}\left(\pi-\cos ^{-1}\left(1-2 \frac{h_{L}}{D}\right)\right) \\
& k_{i}=2 D \sqrt{\frac{h_{L}}{D}\left(1-\frac{h_{L}}{D}\right)}
\end{aligned}
$$

Os diâmetros hidráulicos de ambas as fases são obtidos em função do perímetro de contato.

$$
\begin{aligned}
& D_{h, L}=\frac{4 A_{L}}{k_{L}} \\
& D_{h, G}=\frac{4 A_{G}}{k_{G}}
\end{aligned}
$$

Os perímetros de contato no regime anular para a fase líquida $k_{L^{\prime}}$ gás $k_{G^{\prime}}$ interface $k_{i^{\prime}}$ são mostrados abaixo, sendo $k_{G}=0$, por não existir contato da fase gasosa com a tubulação, a área do líquido na seção transversal $A_{L}$ e área do gás $A_{G^{\prime}}$ e o holdup da fase gasosa. 


$$
\begin{gathered}
k_{L}=\pi D \\
k_{G}=0 \\
k_{i}=\pi D-2 \pi h_{L} \\
A_{L}=\pi h_{L} D-\pi h_{L}^{2} \\
A_{G}=\frac{\pi D^{2}}{4}-\pi h_{L} D+\pi h_{L}^{2} \\
\alpha_{G}=\frac{4 A_{G}}{\pi D^{2}} \\
\alpha_{G}+\alpha_{G}=1
\end{gathered}
$$

O fator de atrito, $f$, é calculado a partir do número adimensional de Reynolds, em função da velocidade da mistura das fases, via diagrama de Moody ou expressões empíricas equivalentes (CHURCHILL, 1977). 30 e 31.

A tensão de cisalhamento deve-se à interação entre a fase gasosa, $\tau_{w g^{\prime}}$ fase líquida $\tau_{w L^{\prime}}$ equações

$$
\begin{aligned}
& \tau_{w G}=f_{G} \frac{\rho_{G} \mathrm{v}_{G}^{2}}{2} \\
& \tau_{w L}=f_{L} \frac{\rho_{G} \mathrm{v}_{L}^{2}}{2}
\end{aligned}
$$

Substituindo-a na equação 12, gera-se o gradiente de pressão total tanto para o regime estratificado como para o regime anular.

\subsection{Regime intermitente}

Considera-se que a unidade do slug possui comprimento $l_{U}$ e possui duas regiões distintas, a segunda região é a do slug que consiste no escoamento de um pistão de líquido contendo bolhas dispersas, que, por sua vez, é composta pela velocidade do líquido $U_{L, S}$ e a velocidade do gás $U_{b}=U_{G, S}$, fração de área de gás $\alpha_{G, S}$. Já a primeira região consiste de uma grande bolha alongada (bolha de Taylor) e por um filme de líquido escoando de forma estratificada. Possui fração de área de gás $\alpha_{G, f}$ ângulo de molhamento $\beta_{f}$, e a velocidade do líquido e do gás são dadas por $U_{L, f}$ e $U_{G, P}$ respectivamente.

Figura 2 - Volume de controle para escoamento intermitente.

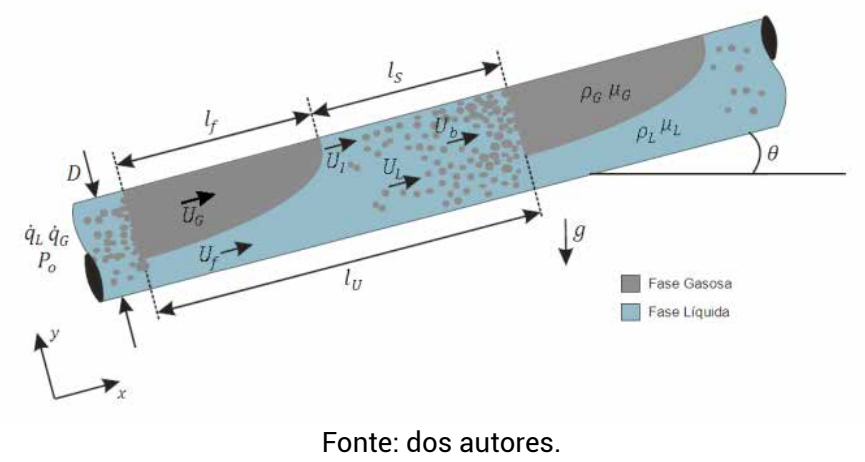


A velocidade translacional do slug, $U_{l^{\prime}}$ pode ser obtida através da seguinte equação, em função da velocidade da mistura.

$U_{I}=(1+C) U_{m}=U_{G}=C_{o} U_{m}+U_{b}$

Para determinar a constante, $C_{o}$, é necessário tomar como base a correlação desenvolvida por Collins et al. (1978).

Realocando as variáveis da equação 32, obtém-se a seguinte equação em função da constante $C$ e $C_{o}$.

$C=\left(C_{o}-1\right)+U_{b} / U_{m}$

Onde $C$ está relacionado à soma do líquido que é perdido na região do filme de líquido e, dentro da unidade de slug, o parâmetro de distribuição, $C_{o}$, obtido por Zuber (1965).

$C_{o}=\mid \begin{array}{cc}2 & \text { Escoam.Laminar } \\ \vdots & \ldots . \ldots \\ \frac{\log \operatorname{Re}_{m}+0,089}{\log \operatorname{Re}_{m}-0,74} & \text { Escoam.Turbulento }\end{array}$

Para o cálculo do holdup de líquido na região do slug, é necessário contemplar alguns componentes como o comprimento do filme de líquido, $I_{f^{\prime}}$ e o comprimento da unidade do slug, $I_{u}$. Quando a lei de conservação de massa para a fase gwasosa é aplicada na unidade do slug e assume que não existe atrito entre as fases, a velocidade na região do slug é igual à velocidade da mistura, $U_{S}=U_{m}$, logo:

$\frac{I_{f}}{I_{U}}=\frac{U_{m}}{U_{I}} \frac{\alpha_{G, S}-\lambda_{L}}{\alpha_{G, S}-\alpha_{L, f}}$

Onde o holdup da fase líquida na região da unidade do slug, $\alpha_{L^{\prime}}$ é calculado a partir do parâmetro $C$, fração de vazio da fase líquida, e o holdup da fase líquida na região do slug, equação 36 .

$\alpha_{L, S}=\frac{C \alpha_{L, f}+\lambda_{L}}{1+C}$

$\alpha_{L, S}=1-\alpha_{G, S}$

Com o conhecimento do holdup de líquido na região do slug (consequentemente, o holdup de líquido na unidade do slug, $\alpha_{\mathrm{L}}$ ), o holdup do filme de líquido, $\alpha_{f}$, comprimento do filme de líquido, $l_{f}$, é possível determinar o gradiente de pressão. 0 termo de atrito e a tensão de cisalhamento, $\tau_{w f}$ e $\tau_{w f}$, e a velocidade do líquido no filme e de gás na bolha de Taylor podem ser determinados a partir das seguintes equações respectivamente. 


$$
\begin{aligned}
\tau_{w b} & =f_{G} \frac{\rho_{G} \mathrm{U}_{G}^{2}}{2} \\
\tau_{w f} & =f_{L} \frac{\rho_{L} \mathrm{U}_{f}^{2}}{2} \\
U_{L, f} & =\left(1-C \frac{\alpha_{L, s}-\alpha_{L, f}}{\alpha_{L, f}}\right) U_{m} \\
U_{G, f} & =\left(1+C \frac{\alpha_{L, s}-\alpha_{L, f}}{1-\alpha_{L, f}}\right) U_{m}
\end{aligned}
$$

Com os valores de holdup, é necessário calcular os valores de diâmetro hidráulico para ambas as fases, equações 21 e 22 e tensão de cisalhamento, equações 38 e 39, para regime estratificado e, para regime anular, o holdup da fase líquida é representado na equação 29 e o perímetro de contato das fases líquida, gasosa e interface entre as fases é representado pelas equações 23,24 , e 25, respectivamente.

Com uma abordagem simples, o fator de atrito no gradiente de pressão na unidade de slug ignora a variação axial na espessura da camada de líquido na parte do filme, logo:

$$
-\left(\frac{d P}{d x}\right)_{F}=\left[\left(\tau_{w f} \frac{K_{f}}{A_{t}}+\tau_{w b} \frac{K_{b}}{A_{t}}\right) \frac{I_{f}}{I_{u}}+2 f_{S} \rho_{S} \frac{U_{m}^{2}}{D} \frac{I_{S}}{I_{u}}\right]
$$

Em posse de todos os parâmetros pertinentes ao gradiente de pressão para tubulações inclinadas, é possível calculá-lo na unidade de slug a partir da seguinte equação:

$$
\left(\frac{d P}{d x}\right)=\left[\left(\tau_{w f} \frac{K_{f}}{A_{t}}+\tau_{w b} \frac{K_{b}}{A_{t}}\right) \frac{I_{f}}{I_{u}}+2 f_{f S} \rho_{S} \frac{U_{m}^{2}}{D} \frac{I_{S}}{I_{u}}\right]-\left[\alpha_{G} \rho_{G}+\left(1-\alpha_{G}\right) \rho_{L}\right] g \sin \theta
$$

Lembrando que o sinal negativo no termo gravitacional se deve ao fato de que a pressão estática diminui, se a posição vertical na tubulação aumenta.

\subsection{Mapas de regimes de escoamento}

A aplicação dos modelos descritos acima depende da determinação do regime de escoamento em cada seção. No presente trabalho segue-se a metodologia descrita por Oliemans e Pots, descrito em Crowe (2006).

0 efeito do ângulo de inclinação da tubulação, $\theta$, é essencial para determinar a transição entre regimes. A maioria dos desenvolvimentos teóricos utilizam tubulações verticais ou pouco inclinadas com escoamento ascendente ou tubulações horizontais e pouco inclinadas, em relação à horizontal.

Assume-se, inicialmente, que o regime seja estratificado, determinando-se o holdup de líquido, conforme visto nos itens anteriores, verificando-se se o regime atende às condições. Caso positivo, aceita-se o regime, verifica-se se é estratificado suave ou ondulado. Caso seja ondulado, verifica-se se existe arraste pelo filme de líquido. Caso seja negativo, o regime é estratificado ondulado com arraste. 
Se o escoamento estratificado não for estável, verifica-se se o regime é anular. Caso seja, verificase a existência da estabilidade pelo filme de líquido e caso seja negativo, o regime é anular com arraste.

Se o regime anular não for possível, verificam-se as condições de estabilidade para os escoamentos de bolhas ou intermitente.

\subsubsection{Procedimento para o cálculo dos regimes de escoamento}

O algoritmo encontra-se sumarizado no fluxograma, na figura 3, e nos passos descritos abaixo.

Passo 1 - São fornecidos: o diâmetro da tubulação, $D$; rugosidade na parede da tubulação, $k$; inclinação da tubulação com a horizontal, $\theta$; velocidade superficial da fase líquida, $v_{S L}$; velocidade superficial da fase gasosa, $v_{S G}$; massa específica da fase líquida, $\rho_{L^{\prime}}$ massa específica da fase gasosa, $\rho_{G^{\prime}} ;$ viscosidade da fase líquida, $\mu_{L} ;$ viscosidade da fase gasosa, $\mu_{G} ;$ e tensão superficial, $\sigma$.

Passo 2 - Calculam-se os números de Reynolds das fases líquida e gasosa, $\operatorname{Re}_{S L}, R_{S G}$, respectivamente; o fator de atrito de Fanning em função da velocidade superficial da fase líquida, $f_{S L}$; e o fator de atrito de Fanning em função da velocidade superficial da fase gasosa, $f_{S G}$, os números de Froude das fases líquida e gasosa, $\mathrm{Fr}_{L}$ e $\mathrm{Fr}_{G}$, respectivamente, o parâmetro de Lockhart e Martinelli, $X$, e o parâmetro de inclinação, $Y$.

Passo 3 - Assume-se que o regime seja estratificado e determina-se o $h_{L} / D$.

Passo 4 - Realiza-se o teste de instabilidade de Kelvin e Helmholtz, em função da altura da camada de líquido.

- Se $\frac{F r_{G}}{(\cos \theta)^{0,5}}>\left(\frac{F r_{G}}{(\cos \theta)^{0,5}}\right)_{\text {Crítico }}$ vá para o passo8.

Passo 5 - Teste de trajetória das gotículas em torno do filme de líquido.

- Se $\theta>0$ então vá para o passo 6 .

$$
\begin{aligned}
& N_{L}^{2}=\frac{f_{S L} F_{L}^{2}}{\cos \theta} \\
& N_{L}>\frac{\left(1-h_{L} / D\right)^{0,5} \alpha_{L}}{\left(f_{L} / f_{S L}\right)^{0,5}}
\end{aligned}
$$

- Calcule o parâmetro $N_{L}$ e determine o $\left(N_{L}\right)_{\text {Crítico }}$, equações 44 e 45 . Se $N_{L}>\left(N_{L}\right)_{\text {crítico }}$, vá para o passo 8 , senão vá para o passo 7 .

Passo 6 - Faça o teste de Jefrey's para interação Vento-Onda para regime estratificado ondulado. 
$K=\left(\frac{\rho_{G}}{\Delta \rho g D}\right)^{0,5} \mathrm{v}_{S G} R e_{S L}^{0,5}$

$K_{C} \geq 2 \alpha_{G}\left(\frac{\alpha_{L} \cos \theta}{0,01}\right)^{0,5}$

- Calcule $K$, equação (46) e determine o $(K)_{\text {crítico }}$. Se $K<(K)_{\text {crítico }}$ o regime é estratificado suave, regime encontrado.

- Caso contrário, o regime é estratificado ondulado. Faça o teste de Kutateladze para o arraste de líquido. Se $\mathrm{Ku}>3,2$, o regime é estratificado ondulado com arraste, caso contrário o regime é estratificado ondulado sem a presença do arraste.

Passo 7 - Teste de ondas gravitacionais. Obtenha o valor de $\left(F_{L}\right)_{\text {crítico }}$.

$F_{L}=\left[\rho_{L} /(\Delta \rho g D)^{0,5}\right] \mathrm{v}_{S L}$

$F_{L}>1,5\left(h_{L} / D\right)^{0,5} \alpha_{L}$

- Se $F_{L}<\left(F_{L}\right)_{\text {crítico }}$ e $\theta<0$, então o regime é estratificado suave, regime encontrado.

- Caso contrário o regime é estratificado ondulado. Faça o teste de Kutateladze, equação 50 para o arraste de líquido. Se $K u>3,2$, o regime é estratificado ondulado com arraste, senão o regime é estratificado ondulado sem a presença do arraste, regime encontrado.

$K u=\frac{\sqrt{\rho_{G}}}{(\Delta \rho g \sigma)^{1 / 4}} \mathrm{v}_{S G}$

Passo 8 - Assume-se que o regime seja anular, determinando o holdup da fase líquida a partir dos parâmetros de Lockhart e Martinelli e inclinação, $X$ e $Y$, respectivamente.

Passo 9 - Verifica-se a estabilidade do filme de líquido em função do $\alpha_{G}=0,35$.

- Se $\alpha_{L}>0,35$, vá para o passo 11 .

- Se $\theta=90^{\circ}$ vá para o passo 10 .

- Caso contrário, o regime é anular. Faça o teste de Kutateladze para o arraste de líquido, equação 47 . Se $K u>3,2$, o regime é estratificado ondulado com arraste, senão o regime é estratificado ondulado sem a presença do arraste, regime encontrado.

Passo 10 - Teste de estabilidade do filme de líquido. Determine o número de Froude crítico para a fase gasosa, equação 51 . 
$F r_{G}^{2}<\frac{75}{E o_{D}^{2}}\left[1+\left(\frac{\left(E o_{D} / 75\right)^{2}}{F_{w}}\right)^{0,5}-1\right]$

$E o_{D}=D(\Delta \rho g / \sigma)^{0,5}$

- Se $\mathrm{Fr}_{G}<\left(\mathrm{Fr}_{G}\right)_{\text {Critico }}$ vá para o passo 11 .

- Senão o regime é anular. Faça o teste de Kutateladze para o arraste de líquido. Se $K u>3,2,0$ regime é estratificado ondulado com arraste, senão o regime é estratificado ondulado sem a presença do arraste, regime encontrado.

Passo 11 - Teste para regime de bolhas dispersas ou intermitente.

- Se $|\theta|<10^{\circ}$ vá para o passo 12.

- Determine o holdup da fase gasosa para o regime de bolhas dispersas equações (3). Se $\alpha_{G}>0,52$, o regime é intermitente, regime encontrado.

- Se $\alpha_{G}<0,25$, regime de bolhas dispersas, regime encontrado.

- Se $0,25<\alpha_{G}<0,52$, determine o tamanho das bolhas a partir das equações 53 até 55 .

$E o_{D}=D(\Delta \rho g / \sigma)^{0,5}$

$d_{\text {máx }}=\left[0,725+4,15\left(\frac{\mathrm{v}_{S G}}{v_{M}}\right)^{0,5}\right]\left(\frac{\sigma}{\rho_{L}}\right)^{0,6}\left(2 \frac{f_{M} \mathrm{v}_{M}^{3}}{D}\right)^{-0,4}$

$d_{\text {migr }}=\frac{3}{8} \frac{\rho_{L}}{\Delta \rho} \frac{f_{M} \mathrm{v}_{M}^{2}}{g \cos \theta}$

- Se $d_{\text {máx }}<d_{\text {def }}$ e $d_{\text {máx }}<d_{\text {migr }}$ então o regime é de bolhas dispersas, senão o regime é intermitente.

Passo 12 - Teste de Flutuações turbulentas x Empuxo. Calcule o parâmetro $T$ e determine o $T_{\text {Critico }}$.

$T^{2}=\frac{\left(d p_{F} / d x\right)_{S L}}{\Delta \rho g \cos \theta}=\frac{2 f_{S L} F r_{L}^{2}}{\cos \theta}$

$T^{2}>2 \pi\left[\frac{\alpha_{L}^{2} \alpha_{G} D}{\left(f_{L} / f_{S L}\right) k_{i}}\right]$

- Se $T>T_{\text {Crítico }}$, então o regime é de bolhas dispersas. Caso contrário, o regime é intermitente. 
Figura 3 - Algoritmo para o cálculo do regime de escoamento.

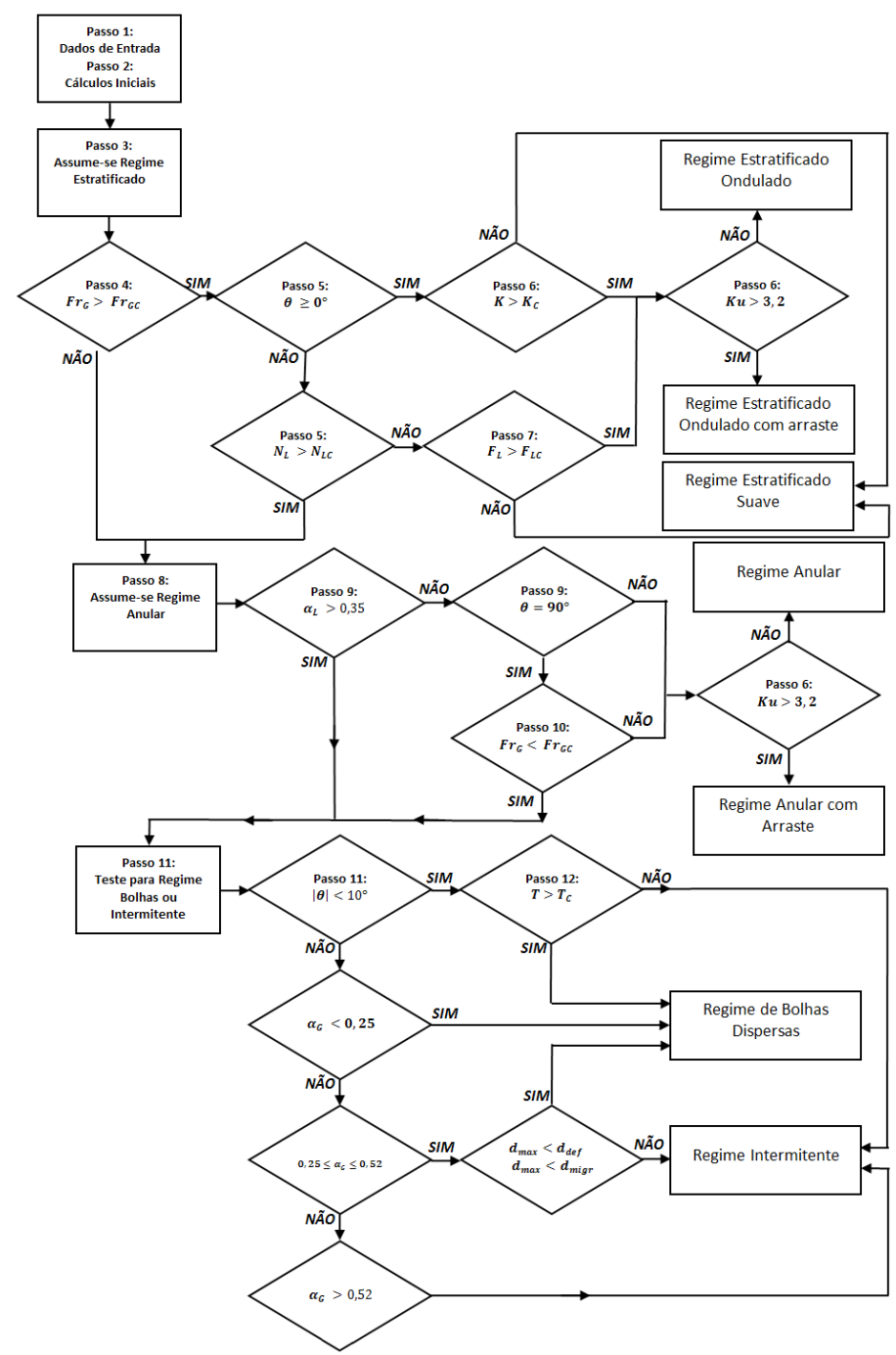

Fonte: dos autores

\subsection{Transmissão de calor em escoamento bifásico gás-líquido}

O coeficiente convectivo entre as fases fluidas e a parede de uma tubulação com escoamento bifásico varia de acordo com o regime ou padrão de escoamento. Isso se deve não só à variação da área de líquido em contato com a parede da tubulação, mas também às significativas diferenças de velocidade entre as fases e a parede da tubulação.

A inclinação tem importância significativa no tipo de regime. Autores como Ghajar (2005), Kim et. al. (2006) determinaram correlações para determinação de coeficientes convectivos bifásicos.

O coeficiente de calor de um escoamento bifásico pode ser determinado como a soma do coeficiente convectivo de cada fase, conforme abaixo.

$$
\begin{gathered}
h_{T P}=\left(1-\alpha_{G}\right) h_{L}+\alpha_{G} h_{G} \\
=\left(1-\alpha_{G}\right) h_{L}\left[1+\left(\frac{\alpha_{G}}{1-\alpha_{G}}\right)\left(\frac{h_{G}}{h_{L}}\right)\right]
\end{gathered}
$$


Os coeficientes de convecção podem ser expressos como funções do número de Reynolds, Prandtl e a razão entre as viscosidades, o que fornece:

$$
\begin{aligned}
& h_{T P}=\left(1-\alpha_{G}\right) h_{L}+\alpha_{G} h_{G} \\
& \left(1-\alpha_{G}\right) h_{L}\left[1+\left(\frac{\alpha_{G}}{1-\alpha_{G}}\right) \frac{f\left(R e, P r, \mu_{N} / \mu_{w}\right)_{G}}{f\left(R e, P r, \mu_{N} / \mu_{w}\right)_{L}}\right] \\
& h_{T P} \\
& =\left(1-\alpha_{G}\right) h_{L}[1 \\
& \left.+\left(\frac{\alpha_{G}}{1-\alpha_{G}}\right) f\left[\left(\frac{R e_{G}}{R e_{L}}\right)\left(\frac{P r_{G}}{P r_{L}}\right)\left(\frac{\left(\mu_{N} / \mu_{w}\right)_{G}}{\left(\mu_{N} / \mu_{w}\right)_{L}}\right)\right]\right]
\end{aligned}
$$

Substituindo-se a definição do número de Reynolds, segue:

$$
\begin{gathered}
h_{T P}=\left(1-\alpha_{G}\right) h_{L} \\
{\left[1+\left(\frac{\alpha_{G}}{1-\alpha_{G}}\right) f\left[\left(\frac{\frac{\rho_{G} V_{G} D}{\mu_{G}}}{\frac{\rho_{L} V_{L} D}{\mu_{L}}}\right)\left(\frac{\operatorname{Pr}_{G}}{P_{L}}\right)\left(\frac{\left(\mu_{W}\right)_{G}}{\left(\mu_{W}\right)_{L}}\right)\right]\right]} \\
h_{T P}=\left(1-\alpha_{G}\right) h_{L}\left[1+\left(\frac{\alpha_{G}}{1-\alpha_{G}}\right) f\left[\left(\frac{\rho_{G}}{\rho_{L}}\right)\left(\frac{v_{G}}{v_{L}}\right)\left(\frac{\operatorname{Pr}_{G}}{\operatorname{Pr}_{L}}\right)\left(\frac{\left(\mu_{W}\right)_{G}}{\left(\mu_{W}\right)_{L}}\right)\right]\right]
\end{gathered}
$$

Após o desenvolvimento algébrico, obtém-se:

$$
\mathrm{h}_{\mathrm{TP}}=\left(1-\alpha_{\mathrm{G}}\right) \mathrm{h}_{\mathrm{L}}\left[1+\mathrm{C}\left[\left(\frac{\alpha_{\mathrm{G}}}{1-\alpha_{\mathrm{G}}}\right)^{\mathrm{m}}\left(\frac{\dot{\mathrm{m}}_{\mathrm{G}}}{1-\dot{\mathrm{m}}_{\mathrm{G}}}\right)^{\mathrm{n}}\left(\frac{\operatorname{Pr}_{\mathrm{G}}}{\operatorname{Pr}_{\mathrm{L}}}\right)^{\mathrm{p}}\left(\frac{\mu_{\mathrm{G}}}{\mu_{\mathrm{L}}}\right)^{\mathrm{q}}\right]\right]
$$

A função fé postulada como definida na forma de uma constante, $C$, e de coeficientes exponenciais, $(m, n, p, q)$ conforme tabela 1.

$$
\mathrm{h}_{\mathrm{TP}}=\left(1-\alpha_{\mathrm{G}}\right) \mathrm{h}_{\mathrm{L}}\left[1+\mathrm{C}\left[\left(\frac{\alpha_{\mathrm{G}}}{1-\alpha_{\mathrm{G}}}\right)^{\mathrm{m}}\left(\frac{\dot{\mathrm{m}}_{\mathrm{G}}}{1-\dot{\mathrm{m}}_{\mathrm{G}}}\right)^{\mathrm{n}}\left(\frac{\mathrm{Pr}_{\mathrm{G}}}{\mathrm{Pr}_{\mathrm{L}}}\right)^{\mathrm{p}}\left(\frac{\mu_{\mathrm{G}}}{\mu_{\mathrm{L}}}\right)^{\mathrm{q}}\right]\right]
$$

Para os efeitos de inclinação no coeficiente bifásico, será necessário acrescentar um termo de inclinação na equação anterior.

$$
\delta=\left(1+\frac{g D \sin \theta}{v_{S L}^{2}}\right)^{r}
$$


Tabela 1- Parâmetros obtidos a partir de dados experimentais para o cálculo do coeficiente convectivo bifásico.

\begin{tabular}{|c|c|c|c|c|c|c|c|c|c|c|c|c|}
\hline \multirow{2}{*}{$\begin{array}{l}\text { Regimes de } \\
\text { Escoamento } \\
\text { (Número de } \\
\text { amostras) }\end{array}$} & \multicolumn{7}{|c|}{ Valores das constantes } & \multicolumn{5}{|c|}{ Intervalo dos parâmetros } \\
\hline & C & $\mathbf{m}$ & $\mathbf{n}$ & $\mathbf{p}$ & $\mathbf{q}$ & $\mathbf{r}$ & $R e_{S L}$ & $\frac{\dot{q}_{G}}{1-\dot{q}_{G}}$ & $\frac{\alpha_{G}}{1-\alpha_{G}}$ & $\frac{\operatorname{Pr}_{G}}{\operatorname{Pr}_{L}}$ & $\frac{\mu_{G}}{\mu_{L}}$ & $\frac{g D \operatorname{sen} \theta}{v_{S L}^{2}}$ \\
\hline $\begin{array}{l}\text { Intermitente, Bolhas/ } \\
\text { Intermitente, Bolhas/ } \\
\text { Intermitente/Anular } \\
\text { (89 amostras) }\end{array}$ & 2,86 & 0,42 & 0,35 & 0,66 & $-0,72$ & 0 & $\begin{array}{c}2468 \text { até } \\
35503\end{array}$ & $\begin{array}{l}6,9.10^{-4} \\
\text { até } 0,03\end{array}$ & $\begin{array}{c}0,36 \text { até } \\
3,45\end{array}$ & $\begin{array}{c}0,102 \text { até } \\
0,137\end{array}$ & $\begin{array}{c}0,015 \text { até } \\
0,028\end{array}$ & -- \\
\hline $\begin{array}{l}\text { Ondulado/anular } \\
\text { (41 amostras) }\end{array}$ & 1,58 & 1,40 & 0,54 & $-1,93$ & $-0,09$ & 0 & $\begin{array}{c}2163 \text { até } \\
4985\end{array}$ & $\begin{array}{c}0,05 \text { até } \\
0,13\end{array}$ & $\begin{array}{c}3,10 \text { até } \\
4,55\end{array}$ & $\begin{array}{c}0,10 \text { até } \\
0,11\end{array}$ & $\begin{array}{c}0,015 \text { até } \\
0,018\end{array}$ & -- \\
\hline $\begin{array}{l}\text { Ondulado (20 } \\
\text { amostras) }\end{array}$ & 27,89 & 3,10 & $-4,44$ & $-9,65$ & 1,56 & 0 & $\begin{array}{c}636 \text { até } \\
1829\end{array}$ & $\begin{array}{c}0,08 \text { até } \\
0,25\end{array}$ & $\begin{array}{c}4,87 \text { até } \\
8,85\end{array}$ & $\begin{array}{c}0,102 \text { até } \\
0,107\end{array}$ & $\begin{array}{c}0,016 \text { até } \\
0,021\end{array}$ & -- \\
\hline $\begin{array}{l}\text { Intermitente (140 } \\
\text { amostras) }\end{array}$ & 0,86 & 0,35 & $-0,8$ & 0,33 & $-0,67$ & 1,75 & $\begin{array}{c}4468 \text { até } \\
26503\end{array}$ & $\begin{array}{l}\text { 9. } 10^{-4} \text { até } \\
0,02\end{array}$ & $\begin{array}{c}0,51 \text { até } \\
3,70\end{array}$ & $\begin{array}{c}0,075 \text { até } \\
0,102\end{array}$ & $\begin{array}{c}0,013 \text { até } \\
0,019\end{array}$ & $\begin{array}{l}0 \text { até } \\
0,718\end{array}$ \\
\hline Anular (155 amostras) & 1,40 & 0,35 & 0,045 & 0,33 & $-0,67$ & 0,26 & $\begin{array}{c}2468 \text { até } \\
9829\end{array}$ & $\begin{array}{c}0,04 \text { até } \\
0,25\end{array}$ & $\begin{array}{c}4,34 \text { até } \\
14,09\end{array}$ & $\begin{array}{c}0,076 \text { até } \\
0,125\end{array}$ & $\begin{array}{c}0,014 \text { até } \\
0,022\end{array}$ & $\begin{array}{l}0 \text { até } \\
4583\end{array}$ \\
\hline
\end{tabular}

(Adaptado GHAJAR, 2005; KIM et. al. 2006).

Essas constantes são descritas a partir de dados experimentais por Ghajar (2005) e por Kim e Ghajar (2006), conforme tabela acima.

Pelo fato de autores como Ghajar (2005) e Kim (2006) não obterem dados experimentais para todos os regimes e inclinações, será efetuado algumas considerações sem perda de exatidão nos resultados. No regime de bolhas, a geometria é a mesma independente da inclinação. Dessa maneira, será usado o primeiro grupo de constantes da tabela 1. Nos regimes anular e intermitente, são utilizadas o grupo de constantes dois e um, respectivamente para o escoamento horizontal e, para o inclinado, o grupo cinco e quatro, respectivamente.

Por último, o regime estratificado, pode ser dividido em suave e ondulado, o primeiro utiliza o terceiro grupo de constantes, sabendo que o número de Reynolds em função da velocidade superficial da fase líquida é menor que 2.400 , e no regime estratificado ondulado o segundo grupo de constantes, conforme tabela 1.

Essas constantes foram divididas dessa forma, através de comparações entre os mapas dos regimes, sabendo-se que seja possível obter regime estratificado suave em escoamentos horizontais e regime estratificado ondulado nas demais inclinações tanto ascendente como descendente, ou seja, em escoamentos inclinados é possível obter os regimes: estratificado ondulado, bolhas dispersas, anular e intermitente.

\subsection{Temperatura bulk}

Para que a mistura bifásica e as fases tenham a mesma temperatura, dita como temperatura bulk, é necessário que se atendam as hipóteses que serão vistas adiante.

Determina-se a evolução da temperatura bulk ao longo da tubulação a partir do balanço de energia interna entre duas seções da tubulação. As constantes, $\mathrm{T}_{\mathrm{ME}}^{\mathrm{B}}$ e $\mathrm{T}_{\mathrm{MS}}^{\mathrm{B}}$, representam as temperaturas bulk na entrada e saída de um segmento da tubulação. A troca de calor com o ambiente marinho, externo à tubulação, é calculada com base na diferença entre a temperatura externa, $T_{M A R}$, e temperatura bulk média da tubulação nesse segmento, onde é utilizado o conceito de uma resistência térmica total entre o interior e o exterior da tubulação, $R_{T}$, conforme equação (67) Os fluxos de massa da fase gasosa e líquida são, respectivamente, $m_{G}$ e $m_{L}$ e $C_{p L}$ e $C_{p G}$, os calores específicos das duas fases. 
Com base em um balanço térmico em regime permanente, a temperatura bulk da mistura bifásica na saída de um segmento de tubulação é dada por:

$\mathrm{T}_{\mathrm{MS}}^{\mathrm{B}}=\frac{\mathrm{T}_{\mathrm{ME}}^{\mathrm{B}}\left(\left(\dot{\mathrm{m}}_{\mathrm{G}} \mathrm{C}_{\mathrm{pG}}+\dot{\mathrm{m}}_{\mathrm{L}} \mathrm{C}_{\mathrm{pL}}\right)-\frac{1}{2 \mathrm{R}_{\mathrm{T}}}\right)+\frac{\mathrm{T}_{\mathrm{MAR}}}{\mathrm{R}_{\mathrm{T}}}}{\left(\left(\dot{\mathrm{m}}_{\mathrm{G}} \mathrm{C}_{\mathrm{pG}}+\dot{\mathrm{m}}_{\mathrm{L}} \mathrm{C}_{\mathrm{pL}}\right)+\frac{1}{2 \mathrm{R}_{\mathrm{T}}}\right)}$

Com a resistência térmica, , sendo fornecida pela expressão:

$\mathrm{R}_{\mathrm{T}}=1 /\left(R_{\text {Mar }}+R_{\text {Parede }}+R_{\text {Bifásico }}\right)$

Onde,

$R_{M a r}=1 /\left(h_{\text {mar }} \pi D_{C E} L\right)$

$R_{\text {parede }}=\left[\log \left(\frac{D_{c a i}}{D}\right) /\left(2 \pi k_{c a i}\right)\right]+\left[\log \left(\frac{D_{c p i}}{D_{c a i}}\right) /\left(2 \pi k_{c p i}\right)\right]$

$+\left[\log \left(\frac{D_{a p}}{D_{c p i}}\right) /\left(2 \pi k_{a p}\right)\right]+\left[\log \left(\frac{D_{a t}}{D_{a p}}\right) /\left(2 \pi k_{a t}\right)\right]$

$+\left[\log \left(\frac{D_{c p e}}{D_{\text {at }}}\right) /\left(2 \pi k_{\text {cpe }}\right)\right]+\left[\log \left(\frac{D_{c e}}{D_{\text {cpe }}}\right) /\left(2 \pi k_{c e}\right)\right]$

$R_{\text {bifásico }}=1 /\left(h_{T P} \pi D L\right)$

$\mathrm{Na}$ tabela 2, são mostrados os demais parâmetros em função da geometria da tubulação. Essas tubulações são compostas por várias camadas e, para cada camada, temos uma condutividade térmica, calor específico, massa específica e a espessura correspondente para cada, conforme Souza (1999), logo.

Tabela 2 - Parâmetros da geometria da tubulação.

\begin{tabular}{lccc}
\hline \multicolumn{1}{c}{ Camada } & $\begin{array}{c}\text { Massa específica } \\
\left(\mathrm{Kg} / \mathrm{m}^{3}\right)\end{array}$ & $\begin{array}{c}\text { Condutividade térmica } \\
(\mathrm{W} / \mathrm{m} . \mathrm{K})\end{array}$ & $\begin{array}{c}\text { Diâmetro } \\
(\mathrm{mm})\end{array}$ \\
\hline Camada Polimérica Externa & $p_{\mathrm{cpe}}=952,9$ & $K_{\mathrm{cpe}}=0,49$ & $D_{\mathrm{cpe}}=209$ \\
\hline Armadura de Tração & $\rho_{\mathrm{at}}=7850$ & $K_{\mathrm{at}}=51,9$ & $D_{\mathrm{at}}=202$ \\
\hline Armadura de Pressão & $\rho_{\mathrm{ap}}=7850$ & $K_{\mathrm{ap}}=51,9$ & $D_{\mathrm{ap}}=193$ \\
\hline Camada Polimérica Interna & $\rho_{\mathrm{cpi}}=1020$ & $K_{\mathrm{cpi}}=0,25$ & $D_{\mathrm{cpi}}=176$ \\
\hline Carcaça de Aço Intertravada & $\rho_{\mathrm{ci}}=7990$ & $K_{\mathrm{ci}}=16,2$ & $D_{\mathrm{ci}}=168$ \\
\hline
\end{tabular}

Fonte: dos autores. 


\section{RESULTADOS}

\subsection{Mapas dos regimes de escoamento}

O algoritmo de previsão do padrão de escoamento a partir de propriedades físicas, padrões geométricos e vazões de cada fase foram empregados para a geração de mapas dos diferentes padrões de escoamento em tubulações, com diferentes inclinações com a horizontal.

O modelo e o algoritmo empregados permitem que se variem sistematicamente diferentes combinações dos números de Froude da fase líquida e gasosa, $F_{L}$ e $F r_{G}$, respectivamente, e se computem a estabilidade dos diferentes padrões de escoamento admitidos. Para tanto, os modelos e algoritmos apresentados foram implementados na linguagem computacional Fortran 90/95, podendo ser utilizado por outros programas.

Para validação da implementação proposta, foram gerados mapas em analogia a aqueles apresentados por Oliemans e Pots, em Crowe (2006). Esses mapas podem ser observados nas figuras 4 a 7 .

Por simplicidade, com exceção da massa específica da fase gasosa, todas as propriedades físicas das fases foram consideradas constantes, com relação à temperatura, embora a dependência com a temperatura possa ser introduzida facilmente em próximos trabalhos.

Para a geração dos mapas foi considerada uma faixa dos números adimensionais de Froude da fase líquida e gasosa, variando de 0,01 a 10, e 0,001 a 10, respectivamente. Cada faixa foi subdividida em 400 pontos. Os demais parâmetros foram: diâmetro interno de 0,1 metros, rugosidade na superfície da tubulação de 0,001 metros, massa específica das fases líquida e gasosa, 610 e $115 \mathrm{Kg} / \mathrm{m}^{3}$, respectivamente, tensão superficial das fases líquida e gasosa de 0,008 e, por último, as viscosidade das fases líquida e gasosa, 0,00035 e 0,000015 PaS.

Nos mapas gerados e apresentados nas figuras 4 a 7, é possível visualizar o comportamento para vários tipos de inclinação, como, horizontal $\left(0^{\circ}\right)$, ascendente em $0,5^{\circ}$, ascendente em $5^{\circ}$, e vertical $\left(90^{\circ}\right)$. Para visualização dos mapas, foram atribuídas cores e números a cada regime de escoamento, conforme a seguinte codificação:

1. Regime estratificado suave;

2. Regime estratificado ondulado;

3. Regime anular;

4. Regime intermitente;

5. Regime de bolhas dispersas;

6. Regime estratificado ondulado com arraste;

7. Regime anular com arraste.

A seguir, são apresentados os mapas gerados pela presente implementação e, para comparação, os mapas, em baixa resolução e em preto e branco, gerados por Oliemans e Pots em Crowe (2006). 
Figura 4 - Comparação para o mapa do regime de escoamento para tubulação horizontal por Crowe, 2006.
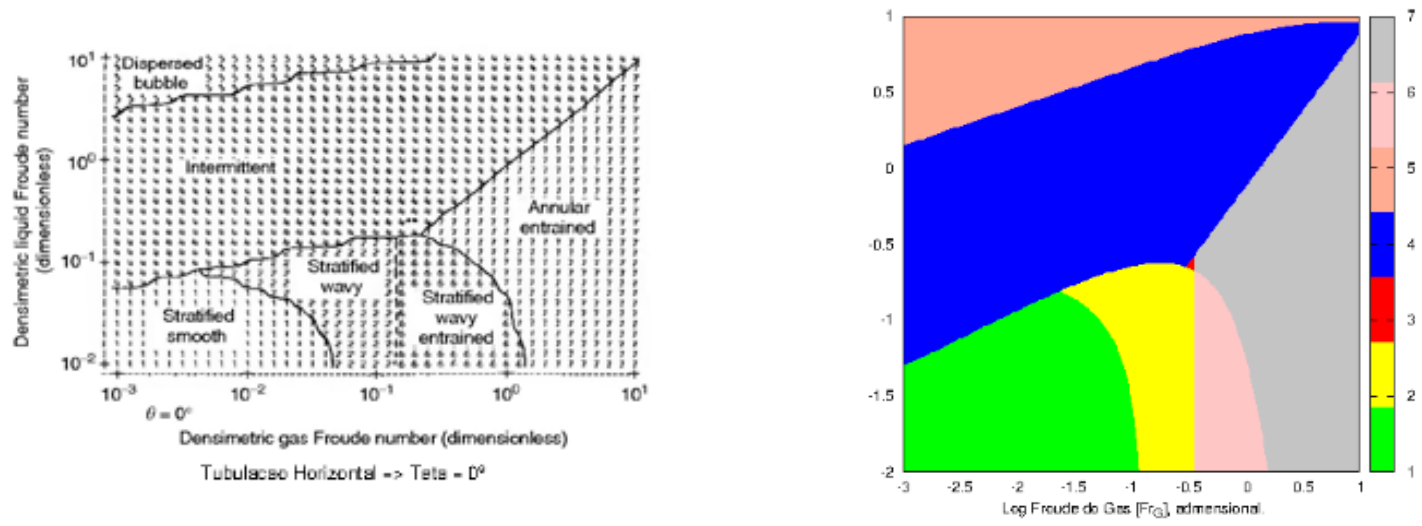

Fonte: dos autores.

Nota-se, na figura 4, que entre o regime estratificado suave e estratificado ondulado existe uma curva decrescente, porém mais acentuada, iniciando com o número de Froude da fase gasosa após 0,01 . Para a linha de interseção entre o regime estratificado ondulado e estratificado ondulado com arraste, foi verificado que o mesmo não apresenta um perfil plenamente vertical, ou seja, com um número de Froude constante, conforme mostrados nos dados experimentais obtidos no gráfico da direita. Devido à maior taxa de refinamento da malha, foi gerada uma região de regime plenamente anular, diferentemente do mapa disponível em Crowe (2006), que exemplifica apenas um regime anular com arraste. Todavia, esse gráfico gerado com o auxílio da ferramenta computacional está muito próximo aos apresentados por Oliemans.

Figura 5 - Comparação para o mapa do regime de escoamento para tubulação ascendente em $0,5^{\circ}$, por Crowe, 2006.
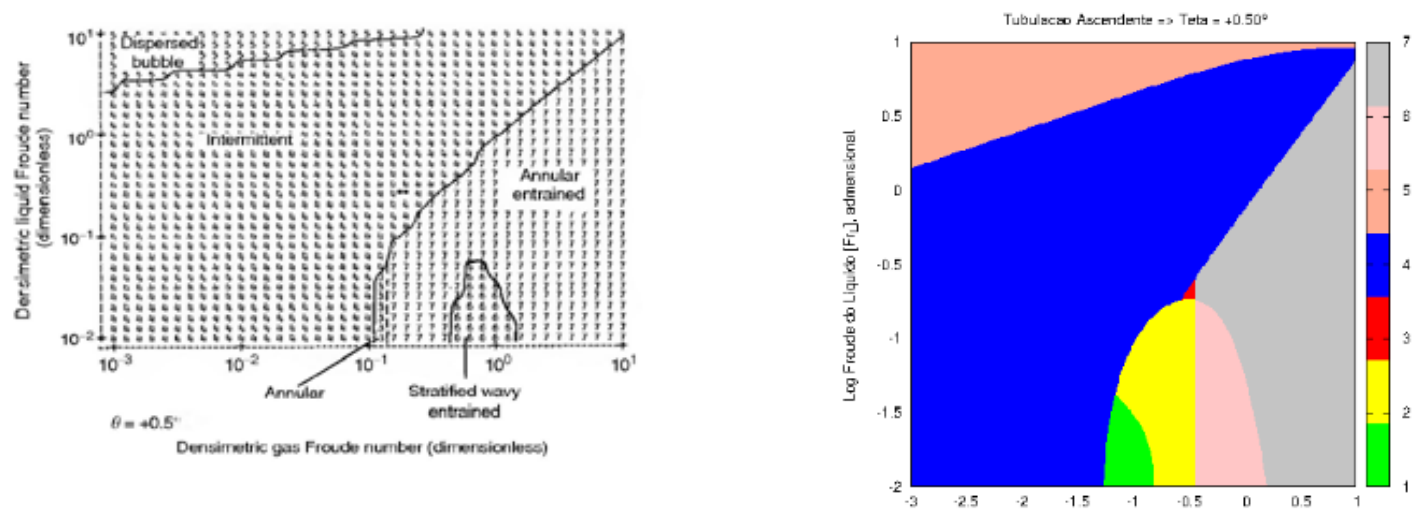

Fonte: dos autores

O mapa proposto com inclinação com a horizontal em $0,5^{\circ}$ apresenta dados aparentemente muito mais consistentes do que os apresentados na referência base deste artigo, com suas curvas mais suaves, com uma pequena modificação da inclinação. 
Figura 6 - Comparação para o mapa do regime de escoamento para tubulação ascendente em $5,0^{\circ}$.
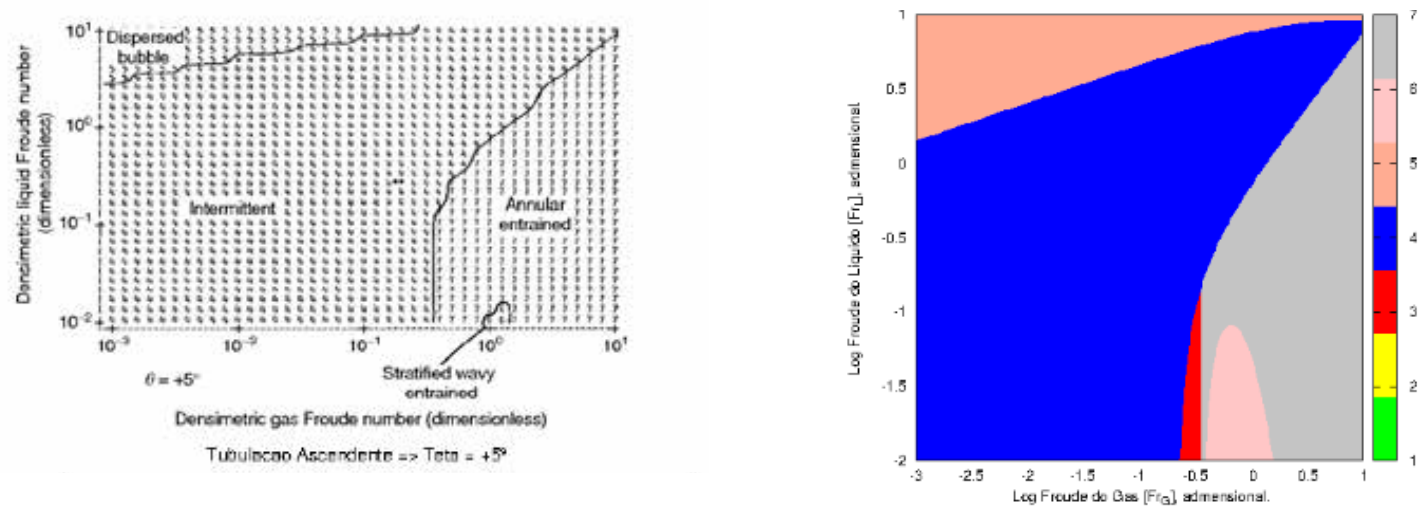

Fonte: dos autores.

A figura 6, além de suas linhas mais suaves, devido ao refinamento do código computacional, apresenta uma pequena região com o regime plenamente anular, o que mostra uma real concordância com os dados do mapa obtidos por Oliemans para $0,5^{\circ}$ de inclinação.

Por último, foi considerado um escoamento com perfil de inclinação em $90^{\circ}$, ou seja, plenamente vertical ascendente, conforme figura 7 . Nota-se que ele apresenta uma pequena região com regime estratificado ondulado com arraste, devido à grande acurácia nos dados obtidos.

Figura 7 - Comparação para o mapa do regime de escoamento para tubulação vertical.
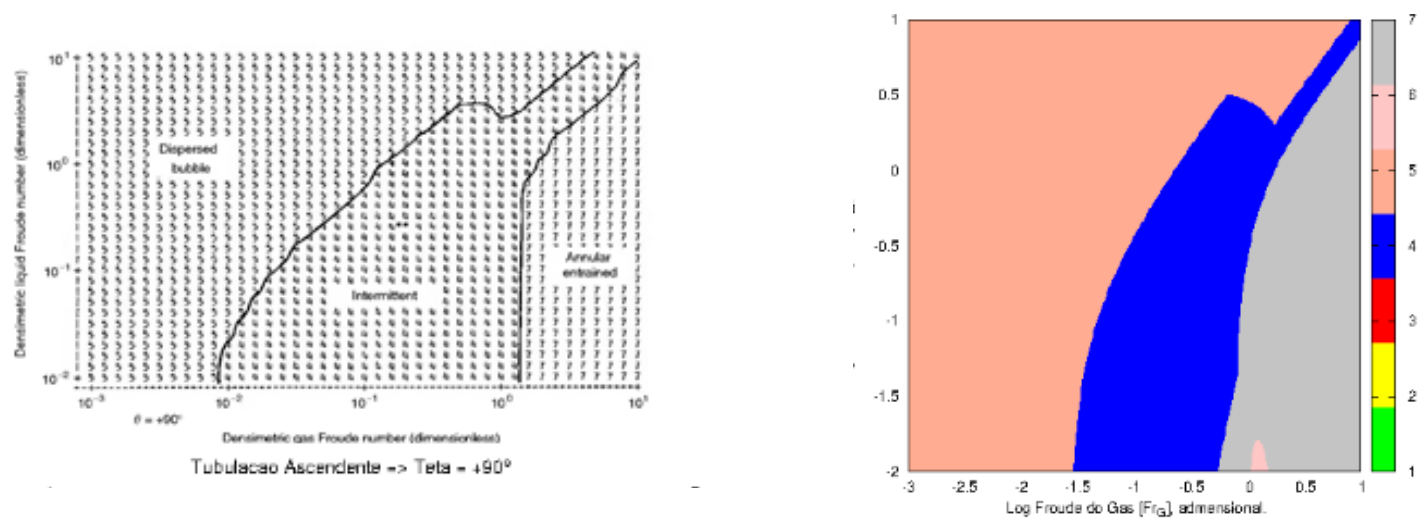

Fonte: dos autores.

\subsection{Escoamento em uma tubulação hipotética}

Com base no algoritmo implementado para determinação dos padrões de escoamento bifásico, procedeu-se, então, com um cálculo da evolução dos regimes ao longo de uma tubulação de perfil hipotético. A massa específica do gás, considerado um gás perfeito de composição $100 \%$ igual a metano - $\mathrm{CH}_{4}$ sofre as variações devido às mudanças acopladas e simultâneas de pressão e temperatura. As variações da massa específica do gás causam variações no número de Froude da fase gasosa, levando a mudanças do regime de escoamento ao longo da tubulação.

Foi postulado o perfil de coluna de produção que aproximasse da realidade da geometria de uma tubulação aplicada na produção de petróleo offshore. 
Para a geração dos gráficos a seguir, foram utilizados os seguintes dados: temperatura da mistura na base da tubulação, $300^{\circ} \mathrm{C}$; pressão do reservatório, $2.000 .000 \mathrm{~Pa}$; constante termodinâmica do gás, $518 \mathrm{~J} / \mathrm{Kg}^{\circ} \mathrm{K}$.

Nota-se, na figura 8, que, para as vazões mássicas das fases gasosa e líquida, fixadas com os mesmo valores, foi possível obter os mapas dos regimes de escoamento em $0,05 \mathrm{Kg} / \mathrm{s}$ e $2,8 \mathrm{Kg} / \mathrm{s}$, respectivamente. Foi gerado um perfil para uma mesma geometria caracterizado por intermitente tanto na horizontal quanto em perfis ascendentes e no plenamente vertical.

Figura 8 - Geometria da tubulação x Regime de escoamento, exemplo 1.

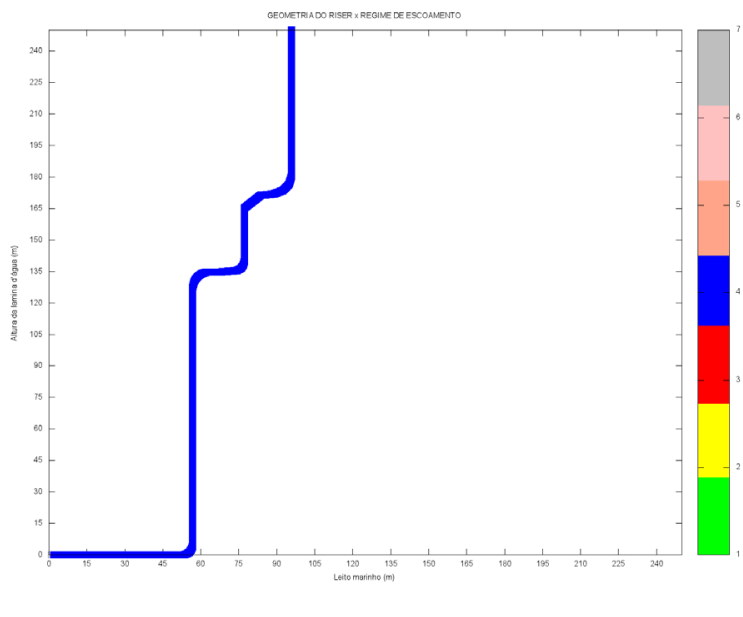

Fonte: dos autores.

No exemplo 2, mostrado na figura 9, foi verificado que, no momento em que foi reduzida a vazão mássica da fase gasosa para $0,0005 \mathrm{Kg} / \mathrm{s}$ e manteve-se fixada a vazão mássica da fase líquida em $2,8 \mathrm{Kg} / \mathrm{s}$, assim foi obtido o regime intermitente nas seções horizontais e bolhas dispersas em tubulações ascendentes e plenamente verticais.

Figura 9 - Geometria da tubulação x Regime de escoamento, exemplo 2.

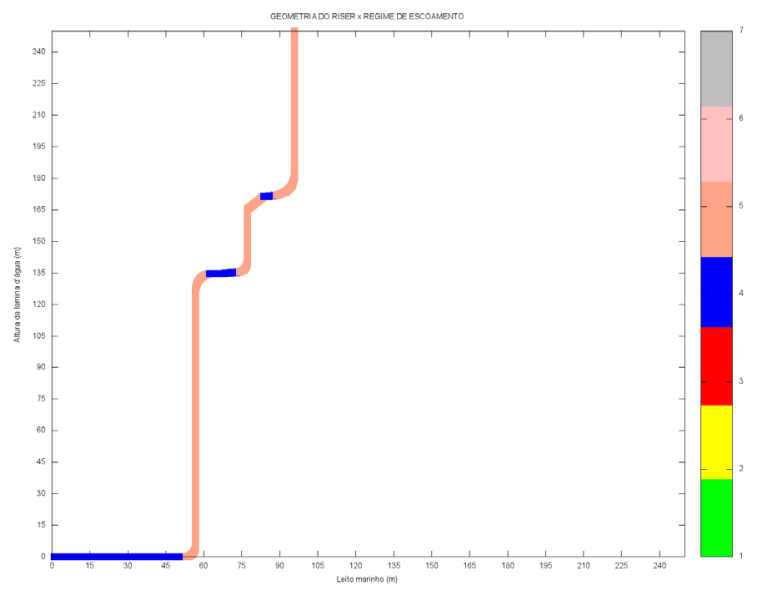

Fonte: dos autores. 
No último exemplo, foi mantida fixa a vazão mássica da fase gasosa em $0,05 \mathrm{Kg} / \mathrm{s}$ e variado a vazão mássica da fase líquida para $0,28 \mathrm{Kg} / \mathrm{s}$, reduzindo-se a vazão desse último em relação ao primeiro exemplo.

Ao iniciar o escoamento no perfil horizontal foi obtido um regime plenamente estratificado ondulado. Na primeira seção vertical, verificou-se o regime intermitente. Conforme visto anteriormente no presente trabalho, existem, nesse regime, duas regiões, nas quais uma se comporta como anular e outra como bolhas dispersas. Ao variar a inclinação da tubulação, foi possível obter, em um pequeno comprimento, o regime estratificado suave, que era esperado, devido ao comportamento fluidodinâmico. Todavia, só foi possível a visualização, devido ao grande número de grid imposto na programação. Por último, foi verificado que, devido a condições de temperatura e pressão impostas na coluna de produção, a última seção vertical apresenta um regime de escoamento de bolhas dispersas.

Figura 10 - Geometria da tubulação x Regime de escoamento, exemplo 3.

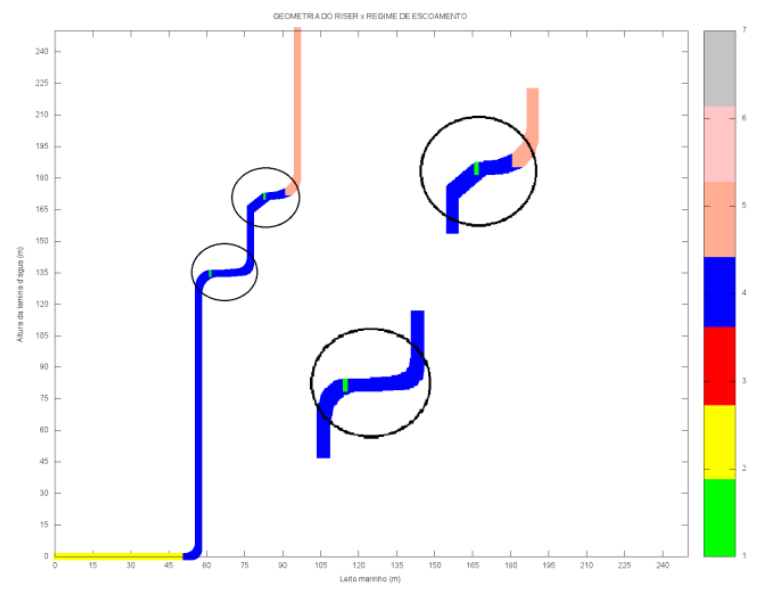

Fonte: dos autores.

\section{CONCLUSÕES}

Um modelo integrado de determinação dos regimes de escoamento, transmissão de calor e queda de pressão em tubulações de exploração de petróleo foi implementado. As previsões de regimes do escoamento bifásico, na forma de mapas de escoamento, reproduzem os resultados da literatura. $\mathrm{Na}$ presente implementação, foi utilizado um maior refinamento na varredura dos números de Froude das fases gasosa e líquida. Os mapas de escoamento apresentam concordância com seus correspondentes gerados por Oliemans e Pots, em Crowe (2006). É digno de nota que tanto os mapas apresentados em Crowe como no presente trabalho carecem ainda de uma rigorosa validação experimental, no que diz respeito ao amplo intervalo de inclinações consideradas para a tubulação.

O algoritmo de determinação de regimes de escoamento foi acoplado com êxito aos modelos de evolução da pressão e de temperatura em uma tubulação de produção de petróleo. Variações de propriedades físicas com a viscosidade e calores específicos em função da temperatura e pressão da mistura podem ser implementados em trabalhos futuros. 


\section{REFERÊNCIAS}

ANDREUSSI, P., An Impedance Method for the Measurement of Liquid Hold-up in Two-Phase Flow. Int. J. Multiphase Flow, 1988.

BENDIKSEN, K.H., An Experimental Investigation of the Motion of Long Bubbles in Inclined Tubes. Int. J. Multiphase Flow, v.10, p. 467-483, 1984.

CHEREMISINOFF, N.P. e DAVIS, E.J., Stratified Turbulent-Turbulent Gás/Líquid Flow, AIChEJ.,25,48-56, 1979.

CHISHOLM, D., A Teorical Basis for the Lockhart-MartinelliCorrelataion for Two-Phase Flow, Int. J. Heat Mass Transfer, 10, 1767-1778, 1967.

CHURCHILL, S.W., Friction Factor Equation Spans All Fluid Flow Regimes, Chem. Eng., 7,91, 1977.

COHEN, L.S., e HANRATTY, T.J., Effect of Waves at a Gas/Liquid Interface on Turbulent Air Flow, J. Fluid Mech., 31, 476-479,1968.

COLEBROOK, C.F., Turbulent Flow in Pipes with Particular Reference to the Transition Region Between the Smooth and Rough Pipe Laws, J. Inst. Civil Eng., 11, 133,1939.

COLLINS, R., de MORAES, F.F., Davidson, J.F., e Harrison, D., The Motion of a Large Gas Bubble Rising Through Liquid Flowing in a Tube, J. Fluid Mech., 89,497-514, 1978.

CROWLEY, C.J., e RATHE, P.H., Assessement of Mechanistic Two-Phase Analysis Methods for GasCondensate Pipelines, PSIG Annual Meeting. Toronto, October, 20-21, 1988.

DUKLER, A. E., TAITEL, Y. Flow Pattern Transitions in Gas-Liquid Systems. Measurement and Modelling. Multiphase Science and Technology, Vol. II, G. F. Hewitt, J. M. Delhaye, and N. Zuber, Eds., Hemiphere, Washington, DC, 1986.

DUKLER, A.E., HUBBARD, M.G., Model for Gas-Liquid Flow in Horizontal and Near Horizontal Tubes, Ind. Eng. Chem. Fundam.,14, 337-347, 1975.

HEYWOOD, N.I., e RICHARDSON, J.F., Slug Flow of Air/WaterMixtures in a Horizontal Pipe: Determination of Liquid Hold-up by -ray absorption,Chem. Eng. Sci., 17-30, 34, 1979.

HINZE, J.O., Fundamentals of the Hydrodynamic Mechanism of Splitting in Dispersion Process, AIChE J.,1, 289-295, 1955.

ISHII, M., e GROLMES, M. A., Inception Criteria for Droplet Entrainment in Two-Phase Concurrent Film Flow, AIChE J., 21, 308-318, 1975.

CARRIZALES,J.M., JARAMILLO, J.E. and. FUENTES, D, Prediction of Multiphase Flow in Pipelines: Literature Review, Ing. Cienc., vol. 11, n. 22, pp. 213-233, julio-diciembre, 2015.

KIM, J., e GHAJAR, A.J., A General Heat Transfer Correlation for Non-Boiling Gas-Liquid Flow with Different Flow Patterns in Horizontal Pipes, I. Journal of Multiphase Flow, 2006. 
LOCKHART, R.W. e MARTINELLI, R.C., Proposed Correlation of Data for Isothermal Two-Phase, TwoComponent Flow in Pipes, Chem. Eng. Prog., 45, 39-45, 1949.

LYONS, W.C., PLISGA, G.J., LORENZ, M.D., Standard Handbook of Petroleum and Natural Gas Engineering, Gulf Professional Publishing - Elsevier, 2016.

MANOLIS, I.G., High Pressure Gas-Liquid Slug Flow, Tese de Doutorado, Imperial College of Science, Inglaterra, 1995.

MIYA, M., WOODMANSEE, D.E., e HANRATTY, T.J., A Model for Roll Waves in Gas/Liquid Flow, Chem. Eng. Sci., 26, 1915-1931, 1971.

OLIEMANS, R.V.A., POTS, B.F.M., e Trompé, N., Modeling of Annular Dispersed Two-Phase Flow in Vertical Pipes, Int. J. Multiphase Flow, 12, 711-732, 1986.

PAN, P., e HANRATTY, T.J., Correlation of Entrainment for Annular Flow in Horizontal Pipes, Int. J. Multiphase Flow, 28, 385-408, 2002.

N-2409, Flexible Pipe, Petróleo Brasileiro S.A., 2 edição, Rev.A, 2003.

POTS, B.F.M., OLIEMANS, R.V.A., and TROMPÉ, N., The KSLA Method for Gas/Liquid Two-Phase Pipe Flow Calculations, KSLA Internal report, 1988.

SHOHAM, O., e TAITEL, Y., StratifiedTurbulent-Turbulent Gás/Líquid Flow in Horizontal and Inclined Pipes, AIChE J., 30, 377-385, 1984.

SOUZA, J.M., Análise Numérica de Risers Flexiveis, Tese de Mestrado, COPPE/UFRJ, M.Sc., Engenharia Civil, 1999.

SPÍNDOLA, R.B., Controle Automático para Injeção Otimizada de Gás em Poços de Petróleo Equipados para Funcionamento com Gás Lift Contínuo, Dissertação de mestrado, Natal, 2004.

RICHTER, H.J., Flooding in Tubes and Annuli, Int. J. Multiphase Flow, 7, 647-658, 1981.

TAITEL, Y. e DUKLER, A. E., A Model for Prediction Flow Regime Transitions in Horizontal and NearHorizontal Gas-Liquid Flow, AIChE Journal, 22, 47-55, 1976.

TAITEL, Y., BARNEA, D., DUKLER, A. E., Modelling Flow Pattern Transitions for Steady Upward Gas-Liquid Flow in Vertical Tubes, AIChE Journal, v. 26, p. 345-354, 1980.

TAITEL, Y., DUKLER A. E., A Model For Predicting Flow Regime Transitions in Horizontal and NearHorizontal Gas-Liquid Flow. AIChE Journal, v. 22, p. 47-55, 1976.

THOMAS, J.E., et. al., Fundamentos de Engenharia de Petróleo, Ed. Interciência, 3-9,15-17, 2001.

ULLMANN, A., ZAMIR, M., e BRAUNER, N., Multi-Holdups in Co-current Stratified Flow in Inclined Tubes, Int. J. Multiphase Flow,29, 1565-1581, 2003.

WALLEY, P.B., Boiling, Condensation, and Gas/Liquid Flow, Clarendon Press, Oxford, 1987.

ZUBER, N., FINDLAY, J.A. Average Volumetric Concentration in Two-Phase Flow Systems, J. Heat Transfer, v. 87, p. 453-468, 1965. 